\title{
Small Radial Compressors: Aerodynamic Design and Analysis
}

\author{
K.A.R. ISMAIL*, C.V.A.G. ROSOLEN, F.J. BENEVENUTO and D. LUCATO
}

State University of Campinas, UNICAMP/FEM/DETF, C.P. 6122 Campinas, SP, Brasil CEP: 13083-970

\begin{abstract}
This paper presents a computational procedure for the analysis of steady one-dimensional centrifugal compressor. The numerical model is based on the conservation principles of mass, momentum and energy, and has been utilized to predict the operational and aerodynamic characteristics of a small centrifugal compressor as well as determining the performance and geometry of compressor blades, both straight and curved.
\end{abstract}

Keywords: Aerodynamic design, Radial compressor, Small compressor, Compressor performance

\section{INTRODUCTION}

The advantages of small centrifugal compressor in comparison to the axial flow type were demonstrated at the end of the 1950s. Nevertheless few models were developed intentionally for aeronautical applications. Independent research programs appeared in the 1960s and 1970s as Pratt \& Whitney, Canada (Kenny, 1984) and National Gas Turbine Establishment (Came, 1978). The real flow field in the compressor is far too complex to be treated analytically. For this reason many simplifications, empirical formulations and other simplifying assumptions are usually adopted to design or predict their performance.

Clements and Artt (1987) analysed the influence of the diffuser geometry on the efficiency and operational range of the compressor, while
Bammert et al. (1979) illustrated the importance of coupling the rotor and diffuser in the calculation of the rotor losses. Senoo (1987) analysed the effect of tip clearance on the compressor flow field and its performance. Stow (1989) revised models and advanced computational methods of potential use in blade design while Kenny (1984) reported progress in the numerical techniques, viscous solutions, flow measuring techniques adaptable to centrifugal compressor testing and new developments in materials. Takeda (1987) realized a comparative study of three computer codes for the design and performance prediction of a centrifugal compressor for small gas turbine unit.

Given the shortage of technical information, experience and know how in this area in Brazil, a small research program devoted to this area was started with the objective of designing a small

*Fax: 55 (019) 239-3722. E-mail: kamal@fem.unicamp.br. 
modular gas turbine unit for emergency and similar applications. The first part of the project handles the centrifugal compressor (Rosolen, 1994) and the associated centrifugal gas turbine (Benevenuto, 1996). The analysis is based upon using refined one-dimensional formulation eliminating the use of empirical factors and equations unless absolutely necessary. As a result the flow, temperature and pressure curves can be evaluated along the stream lines in the rotor, diffuser and spiral duct which help in identifying and pointing corrections to the calculated geometry. Also the proposed model allows the analytical design of straight and curved blades, systematic adjustments when necessary and final evaluation of the performance of the unit as well as the determination of the local flows properties.

\section{FORMULATION}

Applying the first law of thermodynamics to the one-dimensional steady fluid flow in the compressor one can compute the power used in the compression process $P_{\mathrm{c}}$ of the total mass flow $\dot{m}_{\mathrm{t}}$ :

$$
P_{\mathrm{c}}=\dot{m}_{\mathrm{t}} c_{\mathrm{p}}\left(T_{03}-T_{01}\right) .
$$

A sketch of the centrifugal compressor with straight profile and diffuser is presented in Fig. 1. The compression ratio $R_{\mathrm{c}}$ can be calculated in terms of the isentropic efficiency $\eta_{\mathrm{c}}$, the stagnation temperatures at the inlet $T_{01}$ and the outlet $T_{03}$ of compressor and the ratio $\gamma=c_{p} / c_{v}$ :

$$
R_{\mathrm{c}}=p_{03} / p_{01}=\left[1+\eta_{\mathrm{c}}\left(T_{03}-T_{01}\right) / T_{01}\right]^{\gamma /(\gamma-1)} .
$$

Due to the inertia and viscous effects the fluid does not follow the rotor outlet tangential speed $U_{2}$ and a slip factor $\sigma_{2}$ is defined as

$$
\sigma_{2}=1-V_{\text {escor }} / U_{2}
$$

The slip factor is empirical and depends upon the number $n_{\mathrm{r}}$ and geometry $\beta_{\infty 2}$ of the blades and is usually given by Wiesner's formula (Came, 1978), as

$$
\sigma_{2}=1-\left(\cos \beta_{\infty 2}\right)^{1 / 2} / n_{\mathrm{r}}^{0,7}
$$

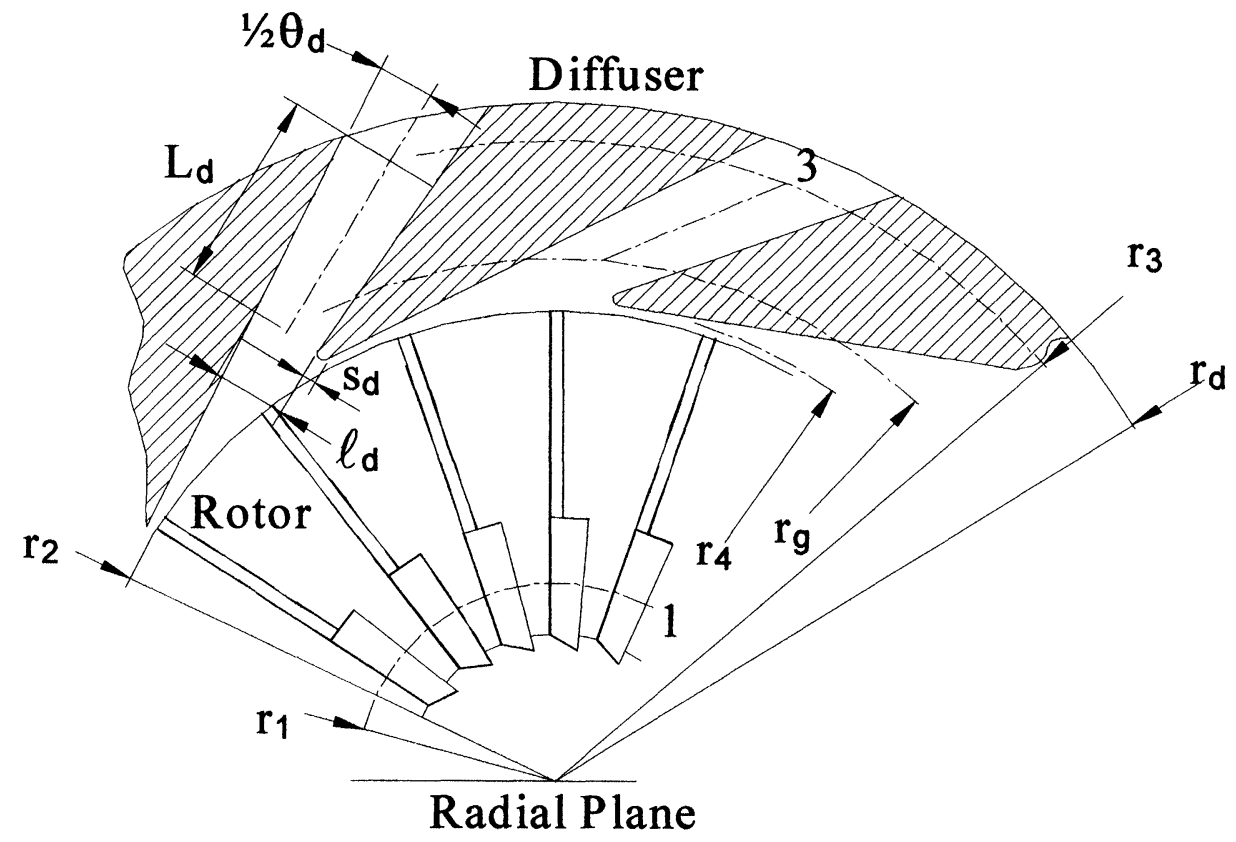

FIGURE 1 Sketch of the centrifugal compressor. 
By using the velocity triangle shown in Fig. 2, for the rotor with curved profile,

$$
C_{\mathrm{w} 2}=\sigma_{2} U_{2}-C_{\mathrm{r} 2} \tan \beta_{\infty 2}
$$

it is possible to define a hypothetical slip factor in the form

$$
\bar{\sigma}_{2}=C_{\mathrm{w} 2} / U_{2} .
$$

Applying the momentum conservation equation between the entry and exit sections of the rotor with rotational velocity $\omega(\mathrm{rad} / \mathrm{s})$ ou $N(\mathrm{rpm})$ one can write

$$
P_{\mathrm{c}}=\dot{m}_{\mathrm{t}} \omega\left(r_{2} C_{\mathrm{w} 2}-r_{1} C_{\mathrm{w} 1}\right) .
$$

Combining Eqs. (1) and (7) and considering that the flow is adiabatic one obtains

$$
T_{02}-T_{01}=\omega\left(r_{2} C_{\mathrm{w} 2}-r_{1} C_{\mathrm{w} 1}\right) / c_{p}
$$

Hence the rotor outlet tangential speed, can be calculated as

$$
U_{2}=\left[c_{p}\left(T_{02}-T_{01}\right) / \bar{\sigma}_{2}\right]^{1 / 2}
$$

The continuity equation is used to calculate the areas and the local flow properties both in the rotor and the diffuser. At the diffuser entrance the tangential velocity component is obtained by considering that the flow in the vaneless space is free vortex type while the other two components are obtained from the mass conservation principle. The flow velocity is assumed constant from entry to the diffuser throat and its direction is assumed constant until the diffuser exit. The fluid is conducted from the throat through diffusing channels to the through spiral duct which is calculated assuming free vortex flow.

In order to determine the total power necessary for running the compressor additional equations are used to estimate the losses. The total power $P$ is the sum of the useful power, $P_{\text {util }}$, the volumetric losses, $P_{\mathrm{vol}}$, the aerodynamic losses, $P_{\mathrm{a}}$, and the mechanical losses $\left(P_{\mathrm{r}}+P_{\mathrm{m}}\right)$ :

$$
P=\left(P_{\text {util }}+P_{\text {vol }}+P_{\mathrm{a}}\right)+\left(P_{\mathrm{r}}+P_{\mathrm{m}}\right)
$$

or

$$
P=\left[\left(P_{\text {util }} / \eta_{\text {vol }}\right)+P_{\mathrm{a}}+P_{\mathrm{r}}\right] / \eta_{\mathrm{m}}^{0}
$$

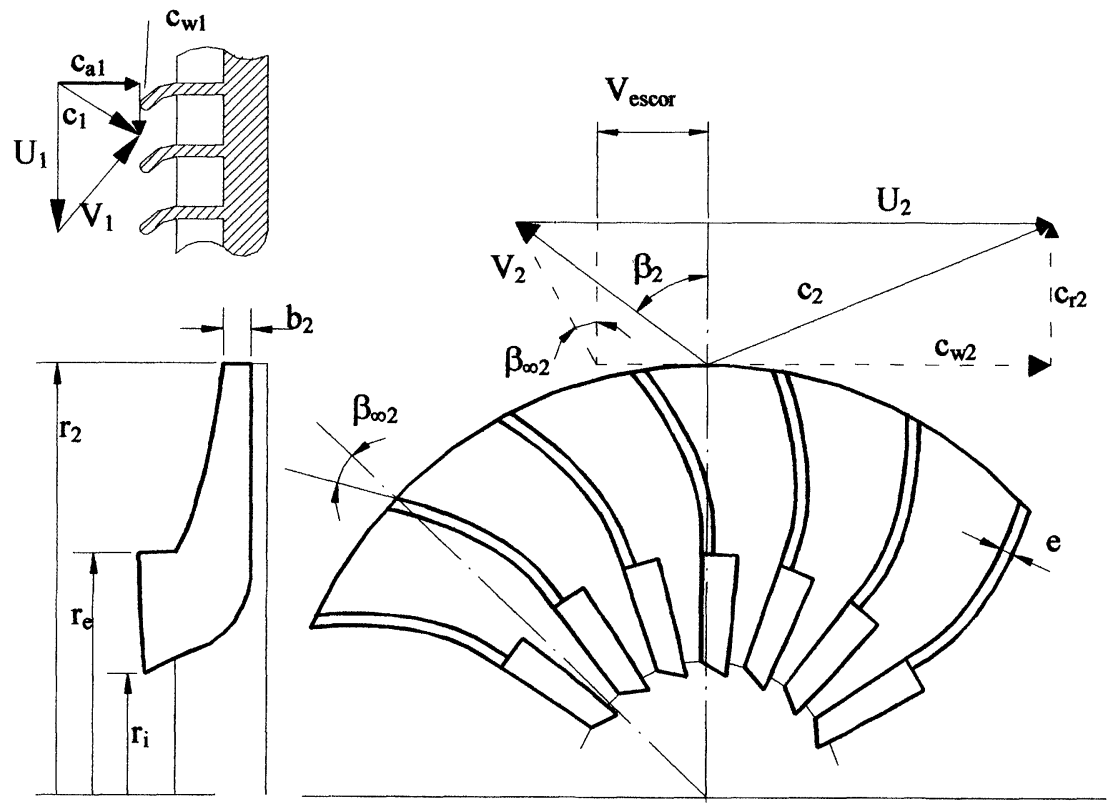

FIGURE 2 Velocity diagrams. 
The useful power is the power used in the real compression process of the net mass flow rate, $\dot{m}$, and is written as

$$
P_{\text {util }}=\dot{m} c_{p}\left(T_{03}-T_{01}\right)
$$

The volumetric efficiency $\eta_{\mathrm{vol}}$ is given by

$$
\eta_{\mathrm{vol}}=\left(\dot{m}_{\mathrm{t}}-\Delta \dot{m}\right) / \dot{m}_{\mathrm{t}}=\dot{m} / \dot{m}_{\mathrm{t}},
$$

where $\Delta \dot{m}$ is the fluid loss in the compressor. The bearing efficiency $\eta_{\mathrm{m}}^{0}$ has been estimated while the disc friction power losses, $P_{\mathrm{r}}$, as well as the aerodynamic losses are calculated in a conventional manner.

The global efficiency $\eta$ has been estimated using as a definition the ratio of isentropic compression power, $P_{\text {is }}$, to the total shaft power,

$$
\eta=P_{\text {is }} / P=\eta_{\mathrm{c}} P_{\mathrm{util}} / P .
$$

The above system of equations is used to calculate and refine the compressor geometry, calculate the local flow properties and finally evaluate the losses and determine the operation parameters of the compressor shown below.

\section{THE CALCULATION PROCEDURE}

The overall operational conditions of the compressor as well as the global geometrical characteristics of the rotor with straight radial blades can be defined using the equations presented. In order to determine the local flow properties and refine the aerodynamic aspect of the blades the rotor is subdivided into three regions in the meridional plane and along the flow direction (see Fig. 3). In the first region, the leading edge of the rotor cascade is tangent to the direction of the flow velocity relative to the rotor. At the end of this region, the rotor cascade is tangent to the axial direction as it is admitted that the flow tangential velocity is compatible with that of the rotor. Between these two sections a cylindrical surface of consistent radius $\mathcal{R}_{\mathrm{g}}$ is adopted for the cascade profile, assuming that the axial velocity is constant while the other properties are calculated. In the second, or intermediate, region the flow direction changes to radial with no slip. In the third region, or exit region, the axial component is considered zero, slip occurs and an expression similar to Eq. (4) is used to calculate the local slip factor.

Expressions similar to Eqs. (6) and (8) are used to calculate the rise in stagnation temperature and pressure between the sections $y$ and $x$ defined by the radius of their mean points, in terms of the politropic efficiency of impeller $\eta_{\infty \mathrm{r}}$, as below:

$$
\begin{aligned}
& T_{0 x}-T_{0 y}=\omega^{2}\left(\bar{\sigma}_{x} r_{x}^{2}-\bar{\sigma}_{y} r_{y}^{2}\right) / c_{p}, \\
& \left(p_{0 x} / p_{0 y}\right)=\left(T_{0 x} / T_{0 y}\right)^{\eta_{\infty \mathrm{r}} \gamma /(\gamma-1)} .
\end{aligned}
$$

In this manner the stagnation properties at a transversal the mean point of each section are obtained while the other properties are calculated from the thermodynamic relations and the conservation equations.

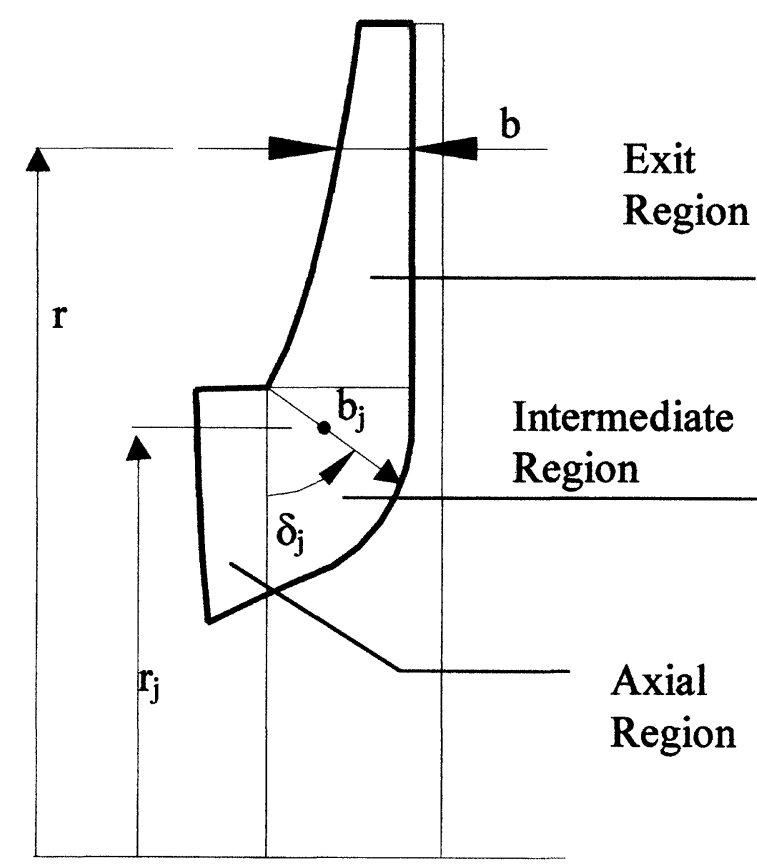

FIGURE 3 Regions of the rotor. 
To improve the accuracy of the calculation procedure the flow passage is subdivided into a number of stream tubes (varying from 1 to 10). The accuracy and the computing time are observed. The procedure for the calculations for each stream tube is practically the same.

Using the one-dimensional basic model it is possible to establish curved blades with a specific exit angle and hence analytically, avoid empirically based curved blades. To achieve this objective the meridional geometry determined for straight radial blades was adopted, together with the rotational velocity and discharge rate. The new operational conditions of the compressor and the flow properties at the rotor exit can be determined. For the intermediate sections of the exit region the radial velocity profile $C_{\mathrm{r}}$ is evaluated from the rotor calculations admitting a hypothetical constant slip factor equal to that of the exit section.

\section{RESULTS AND DISCUSSION}

Based upon this one-dimensional formulation and the proposed calculation scheme a computational code was elaborated to help in the design of centrifugal compressors. This code was then used to determine the effects of the design parameters on the performance of the compressor rotor.

\section{Influence of the Principal Parameters of the Project $R_{\mathrm{c}}, N$ and $P_{\mathbf{c}}$}

The effect of the parameters $R_{\mathrm{c}}, N$ and $P_{\mathrm{c}}$ while keeping the rest of the variables as constants is shown in Table I.

Table II shows the values of $\left(T_{02}-T_{01}\right)$ and $U_{2}$ defined by $R_{\mathrm{c}}$ for rotors of straight profiles. The use of conventional materials limits the value of $R_{\mathrm{c}}$ to about 4 , since $U_{2}$ must not be higher than $460 \mathrm{~m} / \mathrm{s}$ due to the stresses in the material (Cohen et al., 1987).

Tables III and IV present respectively the corresponding values of $r_{2}, N, \dot{m}_{\mathrm{t}}$ and $P_{\mathrm{c}}$ for the pressure ratios $R_{\mathrm{c}}$ used here.
TABLE I Common parameters adopted

\begin{tabular}{lc}
\hline$p_{01}$ & $98.1 \mathrm{kPa}$ \\
$T_{01}$ & $288 \mathrm{~K}$ \\
$\eta_{\mathrm{c}}$ & 0.8 \\
$e$ & $0.003 \mathrm{~m}$ \\
$n_{\mathrm{r}}$ & 19 \\
$\mathcal{R}_{\mathrm{g}}$ & $0.010 \mathrm{~m}$ \\
$\gamma$ & 1.4 \\
$c_{p}$ & $1005 \mathrm{~J} /(\mathrm{kg} \mathrm{K})$ \\
$\mathrm{R}$ & $287 \mathrm{~J} /(\mathrm{kg} \mathrm{K})$ \\
\hline
\end{tabular}

TABLE II Values of $\left(T_{02}-T_{01}\right)$ and $U_{2}$ specified in terms of $R_{\mathrm{c}}$ for rotors of straight profiles $\left(\bar{\sigma}_{2}=0.873\right)$

\begin{tabular}{lcccc}
\hline$R_{\mathrm{c}}$ & 2 & 3 & 4 & 5 \\
\hline$T_{02}-T_{01}[\mathrm{~K}]$ & 79 & 133 & 175 & 210 \\
$U_{2}[\mathrm{~m} / \mathrm{s}]$ & 301 & 391 & 449 & 492 \\
\hline
\end{tabular}

TABLE III Values of $r_{2}$ specified in terms of $R_{\mathrm{c}}$ and $N$

\begin{tabular}{lcccc}
\hline$R_{\mathrm{c}}$ & 3 & & 4 \\
\hline$N[\mathrm{rpm}]$ & 25000 & 30000 & 35000 & 35000 \\
$r_{2}[\mathrm{~m}]$ & 0.149 & 0.124 & 0.107 & 0.122 \\
\hline
\end{tabular}

TABLE IV Values of $\dot{m}_{\mathrm{t}}$ specified in terms of $R_{\mathrm{c}}$ and $P_{\mathrm{c}}$

\begin{tabular}{lccccc}
\hline$R_{\mathrm{c}}$ & \multicolumn{5}{c}{3} \\
\hline$P_{\mathrm{c}}[\mathrm{kW}]$ & 50 & 100 & 113.812 & 150 & 150 \\
$\dot{m}_{\mathrm{t}}[\mathrm{kg} / \mathrm{s}]$ & 0.375 & 0.750 & 0.853 & 1.124 & 0.853 \\
\hline
\end{tabular}

TABLE V Overall parameters of straight blades rotors

\begin{tabular}{lrrrrrrr}
\hline Compressor & A & B & C & D & E & F & G \\
\hline$R_{\mathrm{c}}$ & 3 & 3 & 3 & 3 & 3 & 3 & 4 \\
$N\left[10^{3} \mathrm{rpm}\right]$ & 25 & 30 & 30 & 30 & 35 & 35 & 35 \\
$P_{\mathrm{c}}[\mathrm{kW}]$ & 100 & 50 & 100 & 150 & 100 & 113.8 & 150 \\
$r_{\mathrm{e}}\left[10^{-3} \mathrm{~m}\right]$ & 65 & 50 & 60 & 65 & 60 & 60 & 60 \\
$r_{\mathrm{i}}\left[10^{-3} \mathrm{~m}\right]$ & 35 & 28 & 30 & 22 & 35 & 30 & 30 \\
$C_{\mathrm{a} 1}[\mathrm{~m} / \mathrm{s}]$ & 84 & 78 & 97 & 107 & 110 & 112 & 112 \\
$b_{2}\left[10^{-3} \mathrm{~m}\right]$ & 5.5 & 3.6 & 5.8 & 8.0 & 6.1 & 6.9 & 5 \\
\hline
\end{tabular}

The overall values calculated for the compressors denominated A to $\mathrm{G}$ with rotors of straight geometry are presented in Table $\mathrm{V}$. 

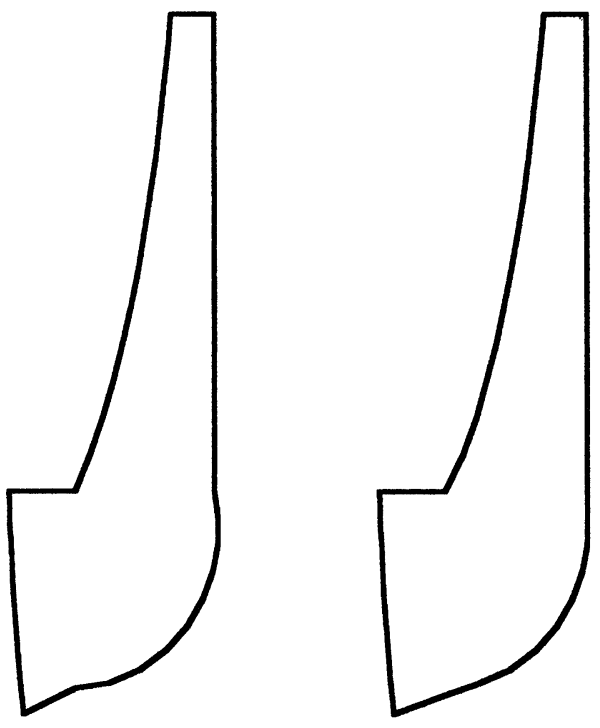

(a) without correction

(b) corrected

FIGURE 4 Meridional geometry of rotor C.

Figures 4-9 present the internal geometry of the rotor calculated based upon subdividing the flow passage into ten stream tubes while the flow properties are presented only for the extreme stream tubes, that is, 1 and 10 .

One can observe from Fig. 4 that the meridional geometry results in discontinuities in the transition sections between the rotor regions because of the different formulations adopted in each region. The correction of the geometry is done by tracing two tangents to the blade root profile; one passing by the inner point of the entry section and the other passing by the point of greatest axial coordinate while maintaining the same radial direction until the rotor exit. The local depth of the sections increases and the local flow properties are recalcu-

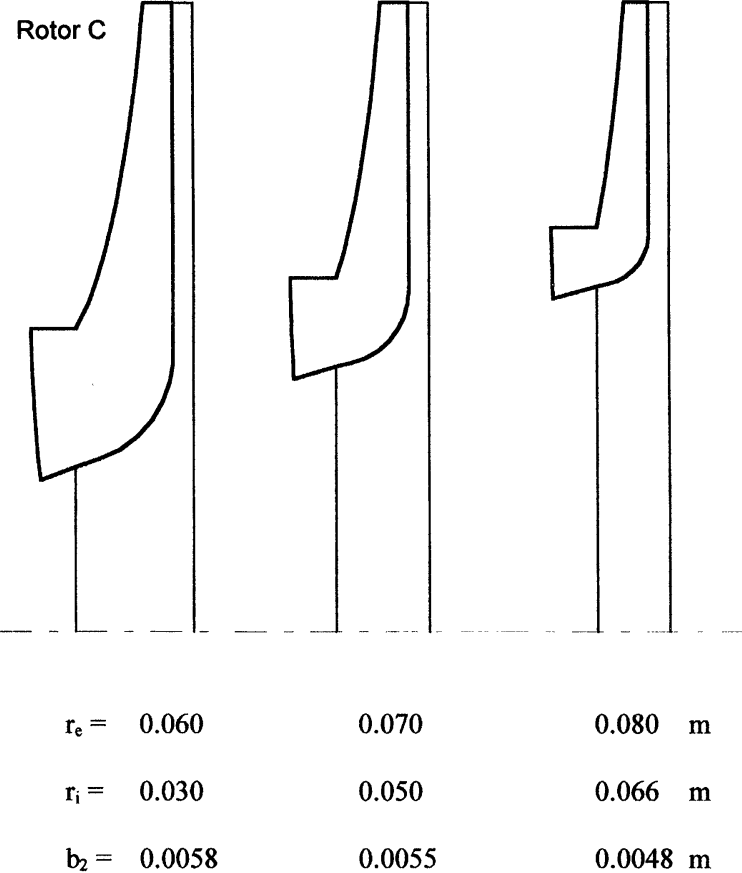

FIGURE 5 Effect of $r_{\mathrm{e}}$ on the rotor geometry.

lated. The maximum variation obtained in the velocity is $1.5 \%$.

The recommendation of positioning the entry section at small radii to obtain deeper rotor passages is illustrated in Fig. 5 which illustrates the variations of rotor $\mathrm{C}$ of Table $\mathrm{V}$.

Figure 6 shows the influence of the rotor velocity. One can observe that the effect of the increase of $N$ is to decrease $r_{2}$ in order to maintain the peripheral velocity $U_{2}$ defined by $R_{\mathrm{c}}$ as in Tables II and III.

Keeping the pressure ratio and the rotor rotational speed as constants, the increase of the value of $P_{\mathrm{c}}$ leads to corresponding increase in the depth of the flow passages of the rotor as in Fig. 7.

Figure 8 shows the effect of the pressure ratio on the compressor geometry. This was achieved by keeping the mass flow rate and the rotor rotational velocity as constants while increasing the value of $R_{\mathrm{c}}$. Then rotor flow passages are found to increase radially. 


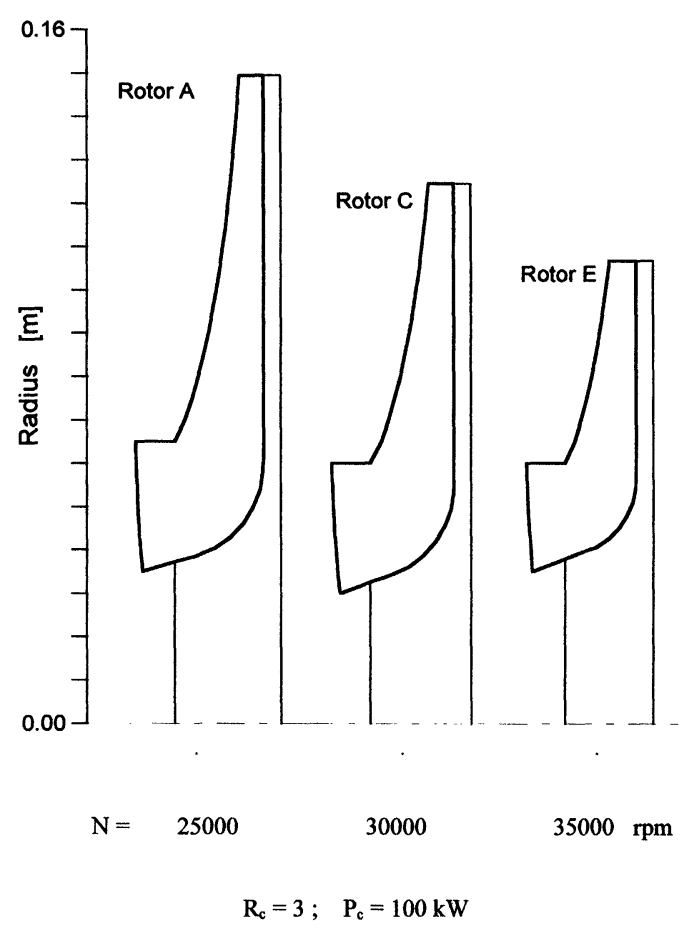

FIGURE 6 Effect of the rotor rotational velocity.

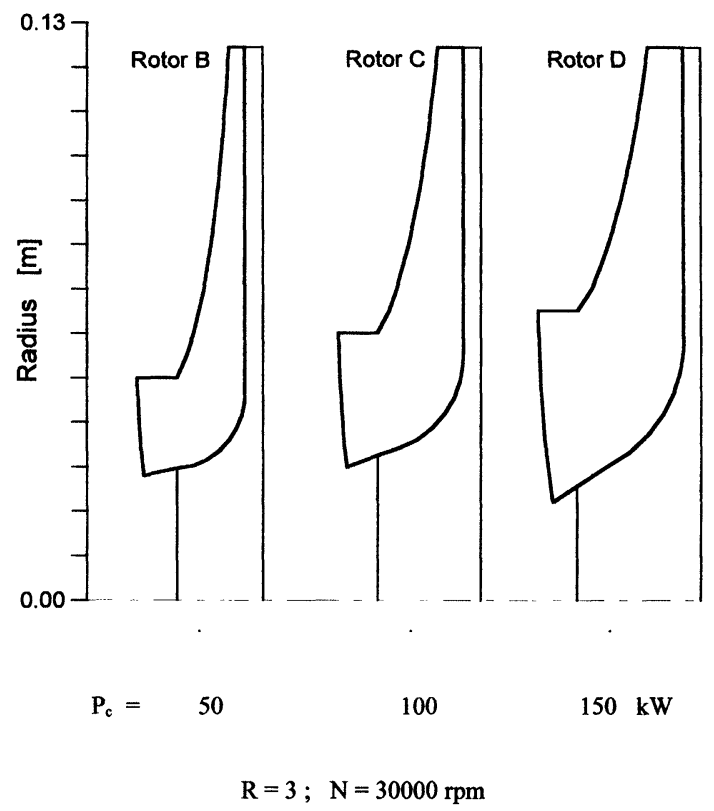

FIGURE 7 Effect of the rotor geometry on the compression power.

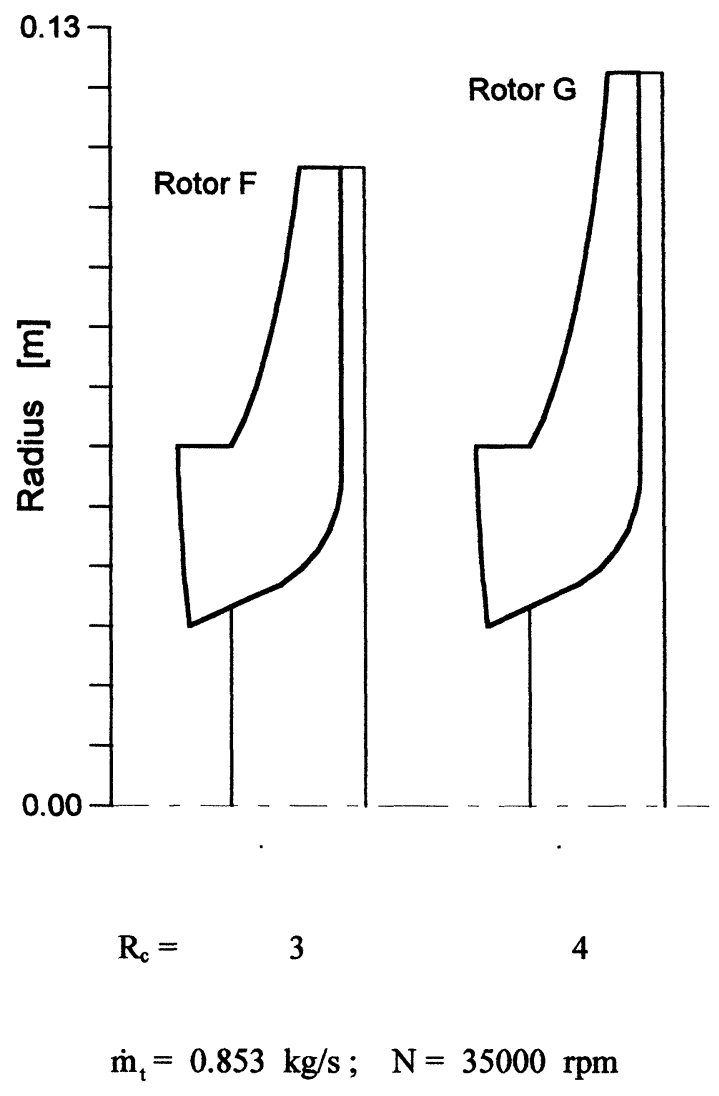

FIGURE 8 Effect of the pressure ratio on the compressor geometry.

\section{Rotor with Straight Blades}

Although the calculations were realized for pressure ratio up to 4 , we chose a minor value of 3 to keep the peripheral velocity well below its limiting value. For the intermediate velocity of $30000 \mathrm{rpm}$, one can observe from Fig. 7 that the depth of the flow passages is very small for $P_{\mathrm{c}}=50 \mathrm{~kW}$, case B, while for $P_{\mathrm{c}}=150 \mathrm{~kW}$, as can be verified from Table VII, the compressor D is also adequate. Hence the option $D$, whose blade profile is shown in Fig. 9, is chosen to present the results illustrating the proposed calculation methodology.

The geometry of the rotor $\mathrm{D}$ with straight blades is presented in Fig. 10 while the pressure and temperature distributions along the flow passages are shown in Figs. 11 and 12. 


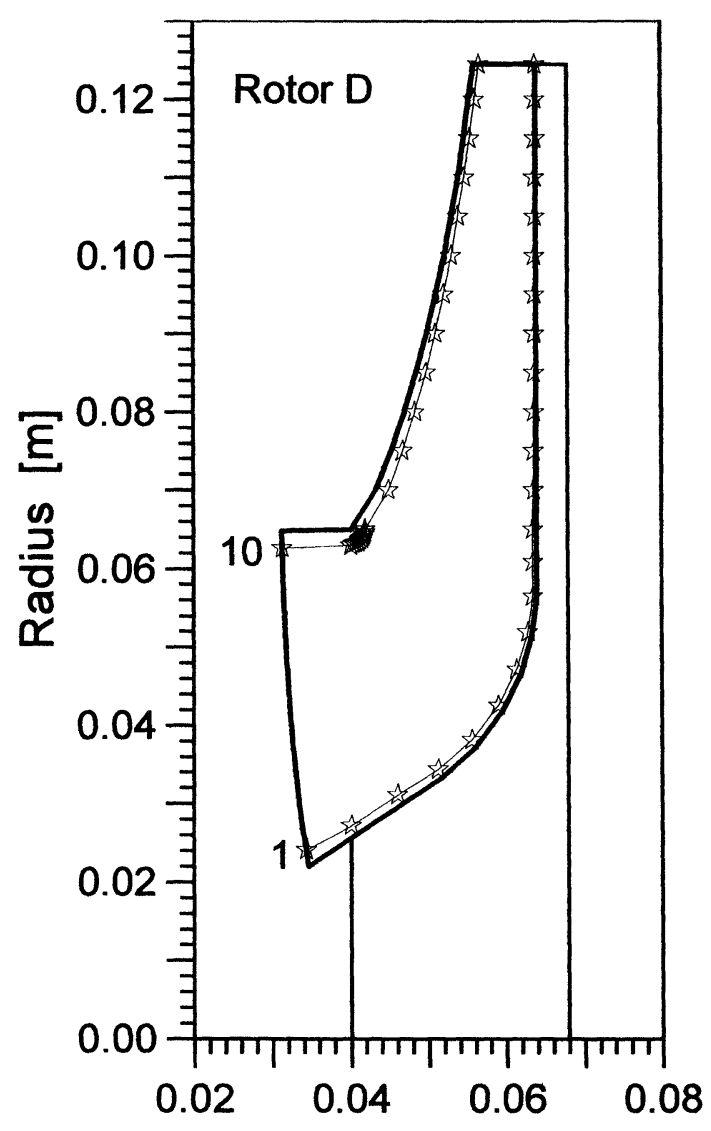

FIGURE 9 Meridional geometry of rotor D.

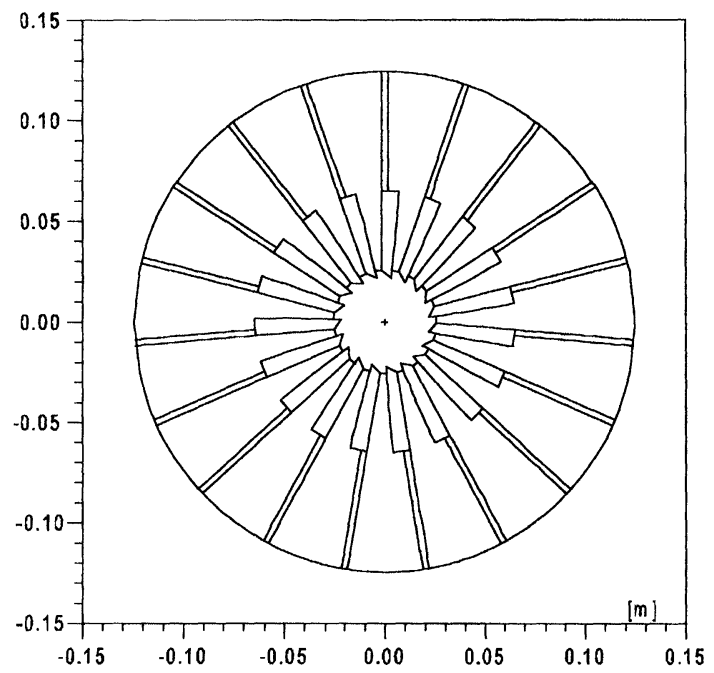

FIGURE 10 Radial geometry of the rotor D with straight radial blades.

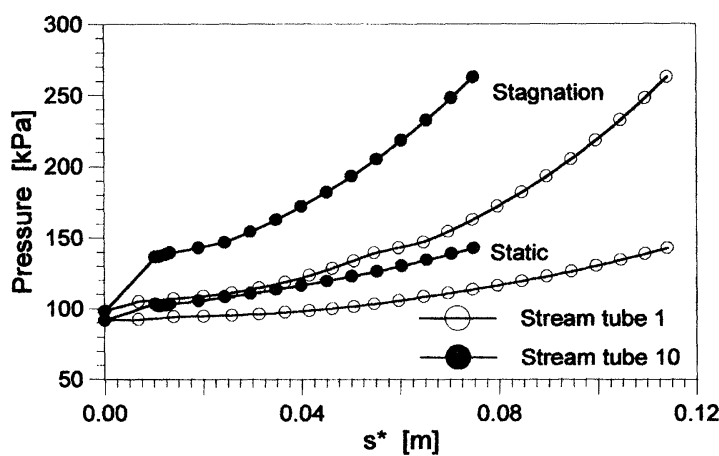

FIGURE 11 Variation of the local static and stagnation pressures (rotor D with straight radial blades).

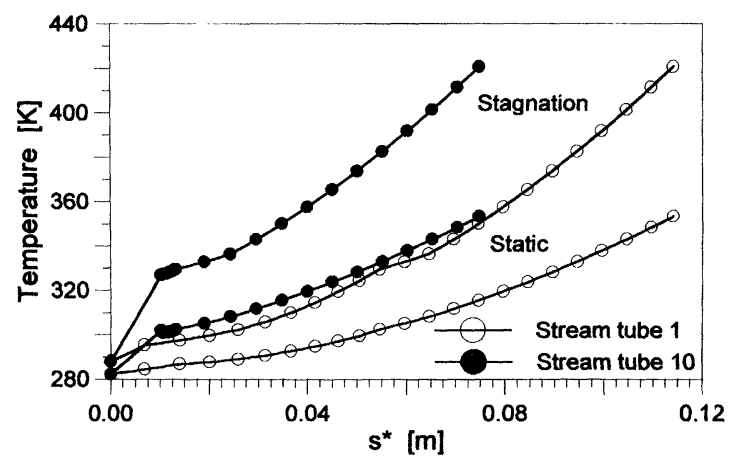

FIGURE 12 Variation of the local static and stagnation temperatures (rotor D with straight radial blades).

\section{Rotor with Curved Blades}

For the calculation of the compressor with curved blades, we used the same meridional geometry obtained for the case of straight blade of Fig. 9. By keeping the same rotor rotational velocity $N$, one recalculates the operational conditions for the angle $\beta_{\infty 2}=30^{\circ}$, as suggested by Takeda (1987). Table VI shows the data values obtained for both compressors, rotors with straight and curved blades. One can also observe that for the compressor with curved blades the pressure ratio is smaller, also the compression power is equally smaller while the angles of the blade exit $\beta_{\infty 2}$ and the flow exit angle $\beta_{2}$ are very close.

In case of the rotor $\mathrm{D}$ with curved blades the pressure and temperature distributions along the 
TABLE VI Compressor D with rotors of straight and curved blades

\begin{tabular}{lcc}
\hline Rotor D & Straight blades & Curved blades \\
\hline$\beta_{\infty 2}$ & $0^{\circ}$ & $30^{\circ}$ \\
$R_{\mathrm{c}}$ & 3 & 2.5 \\
$T_{02}-T_{01}[\mathrm{~K}]$ & 133 & 109 \\
$U_{2}[\mathrm{~m} / \mathrm{s}]$ & 391 & 391 \\
$N[\mathrm{rpm}]$ & 30000 & 30000 \\
$r_{2}[\mathrm{~m}]$ & 0.124 & 0.124 \\
$P_{\mathrm{c}}[\mathrm{kW}]$ & 150 & 123.3 \\
$\dot{m}_{\mathrm{t}}[\mathrm{kg} / \mathrm{s}]$ & 1.124 & 1.124 \\
$r_{\mathrm{e}}[\mathrm{m}]$ & 0.065 & 0.065 \\
$r_{\mathrm{i}}[\mathrm{m}]$ & 0.022 & 0.022 \\
$C_{\mathrm{a} 1}[\mathrm{~m} / \mathrm{s}]$ & 107 & 107 \\
$C_{\mathrm{r} 2}[\mathrm{~m} / \mathrm{s}]$ & 107 & 111 \\
$\beta_{2}$ & $24.9^{\circ}$ & $44.9^{\circ}$ \\
$\sigma_{2}$ & 0.873 & 0.882 \\
$\bar{\sigma}_{2}$ & 0.873 & 0.718 \\
\hline
\end{tabular}

stream tubes 1 and 10 without any corrections are presented in Figs. 13(a) and (b) indicating discontinuities due to the adopted assumptions for the slip factor in the intermediate and exit regions of the rotor. This factor changes abruptly from a unit constant value in the intermediate region to an assumed low value at exit. The correction is based upon using smooth and continuous variation of the slip factor. Hence in evaluating $C_{\mathrm{r}}$ the slip factor instead of being adopted as constant and equal to $\bar{\sigma}_{2}$, is compared to the minimum value necessary to keep the stagnation temperature higher or equal to that of the previous section. Also in the calculation of the blade inclination $\beta_{\infty}$ in the radial plane of the exit region, the slip factor is assumed in the start such that the variation of the stagnation temperature is the same for the three initial sections and starting from the last of these sections, Eq. (4) is used for the slip factor calculations.

The properties distribution after the corrections of the slip factor are shown in Fig. 14. As can be noticed the discontinuities near the rotor exit remained and the blade profile in the radial plane does not tend the value $\beta_{\infty 2}=30^{\circ}$. In the calculation of the $C_{\mathrm{r}}$ profile, the variation of the tangentially projected thickness is not included together with the variation of the slip factor. Hence the correction of $C_{\mathrm{r}}$ is based basically upon
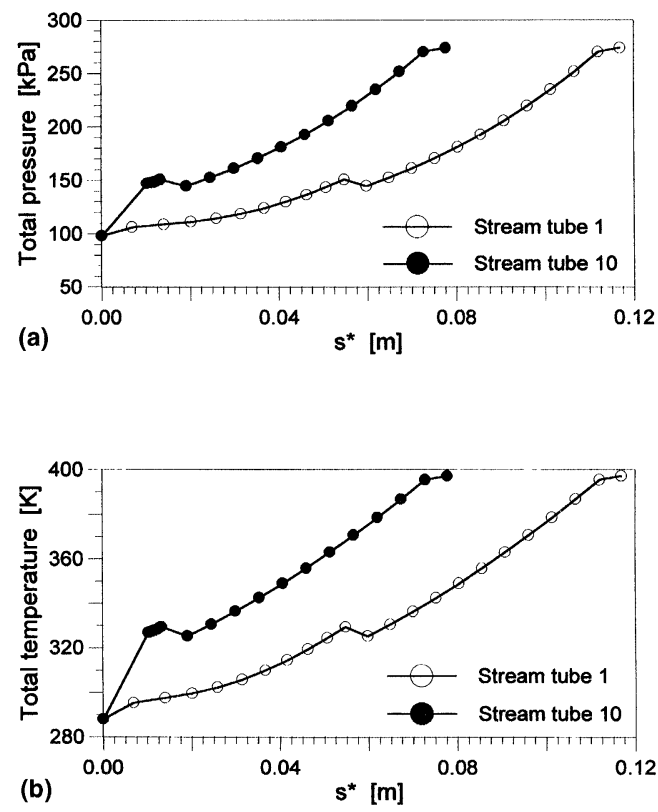

FIGURE 13 (a) Variation of the local stagnation pressure in the rotor with curved blades and without corrections in $\bar{\sigma}_{2}$ and $C_{\mathrm{r}}$. (b) Variation of the local stagnation temperature in the rotor with curved blades and without corrections in $\bar{\sigma}_{2}$ and $C_{\mathrm{r}}$.
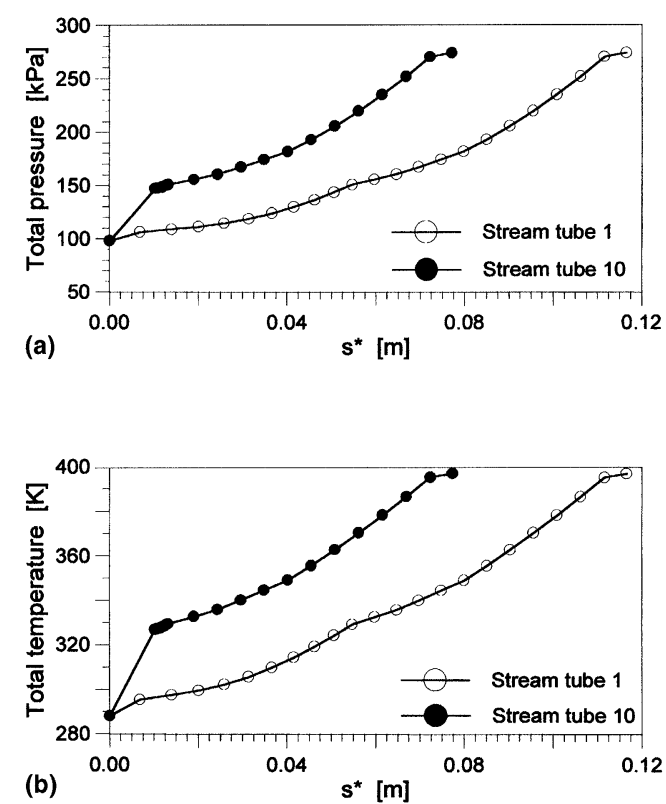

FIGURE 14 (a) Variation of the local stagnation pressure in the rotor with curved blades without correction in $C_{\mathrm{r}}$. (b) Variation of the local stagnation temperature in the rotor with curved blades without correction in $C_{\mathrm{r}}$. 
redistribution of the slip factor and considering the projected thickness effect.

Figures 15 and 16 present the distributions of the static and stagnation properties (pressure and temperature) while Fig. 17 presents the rotor geometry with curved blades. Figure 18 shows a comparison with the rotor with circular arc blade profile.

Following the same method used for the compressor option $\mathrm{D}$, the details of the options $\mathrm{A}$ to $\mathrm{G}$ are calculated, and presented in Table VII. One must notice that the compressor option D presents higher overall efficiency than that of compressor option C.

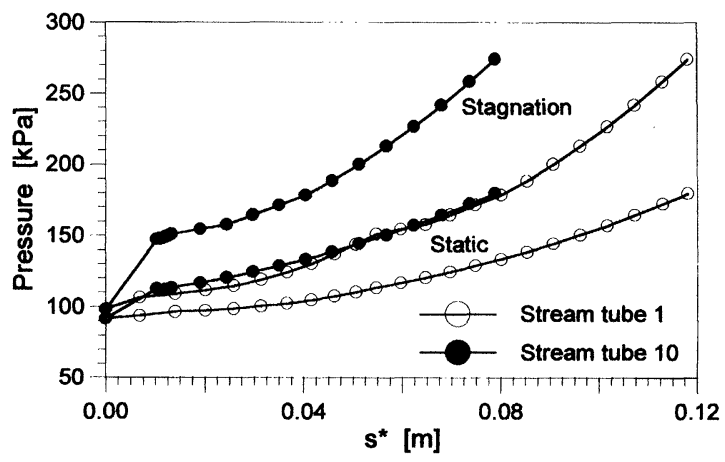

FIGURE 15 Variation of the local static and stagnation pressures (rotor D with curved blades).

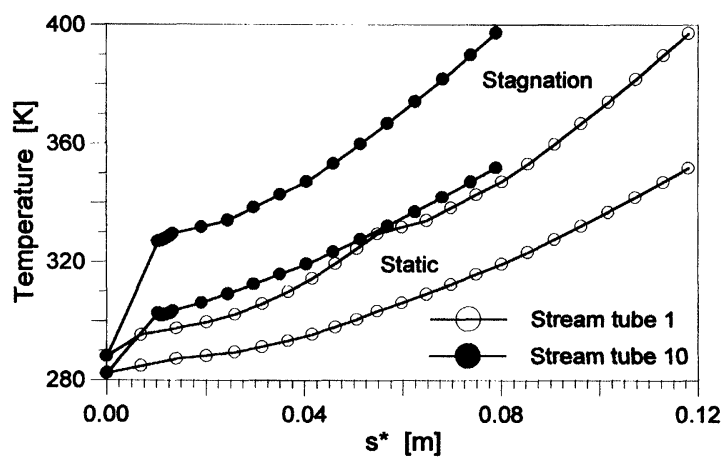

FIGURE 16 Variation of the local static and stagnation temperatures (rotor D with curved blades).

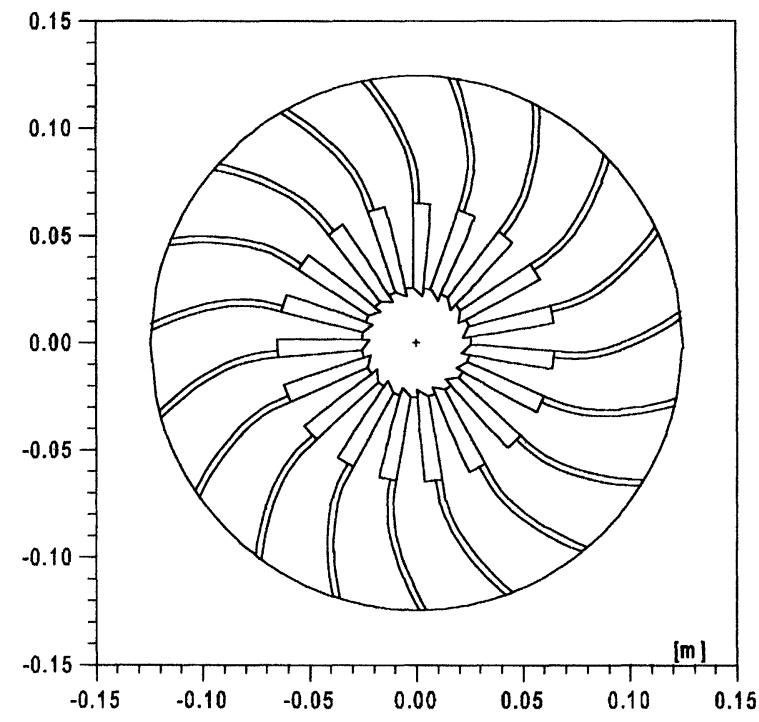

FIGURE 17 Radial geometry of the rotor D with curved blades $\left(\beta_{\infty 2}=30^{\circ}\right)$.

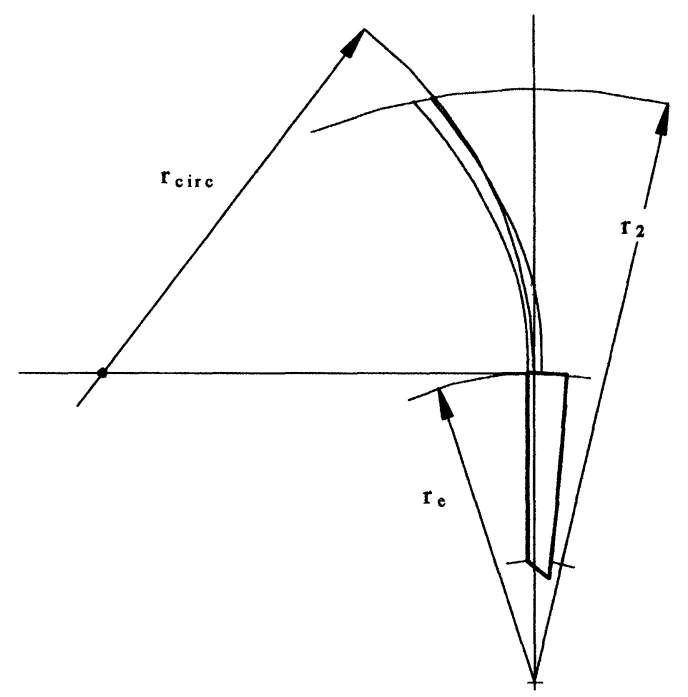

FIGURE 18 Comparison of analytically curved blade design with circular arc blade profile.

\section{CONCLUSION}

The most important conclusion of the present study is that the proposed model is able to predict the overall working parameters, the local flow properties, the compressor performance characteristics and finally enables refining the rotor geometry and predict its new performance. 
TABLE VII Compressors with curved blades rotors $\left(\beta_{\infty 2}=30^{\circ}\right)$

\begin{tabular}{|c|c|c|c|c|c|c|c|c|}
\hline & $R_{\mathrm{c}}$ & $\Delta T_{0}[\mathrm{~K}]^{\dagger}$ & $P_{\mathrm{c}}[\mathrm{W}]$ & $\dot{m}[\mathrm{~kg} / \mathrm{s}]$ & $P_{\mathrm{a}}[\mathrm{W}]$ & $P_{\mathrm{r}}[\mathrm{W}]$ & $P[\mathrm{~W}]$ & $\eta[\%]$ \\
\hline A & 2.63 & 115 & 86347 & 0.723 & 13606 & 2514 & 103499 & 64.41 \\
\hline B & 2.66 & 116 & 43693 & 0.355 & 7384 & 1886 & 53493 & 61.89 \\
\hline $\mathrm{C}$ & 2.57 & 111 & 84028 & 0.724 & 14398 & 1857 & 101296 & 64.08 \\
\hline $\mathrm{D}$ & 2.53 & 109 & 123342 & 1.098 & 21439 & 1840 & 148101 & 65.04 \\
\hline $\mathrm{E}$ & 2.51 & 108 & 81578 & 0.721 & 16592 & 1432 & 100605 & 62.38 \\
\hline $\mathrm{F}$ & 2.50 & 108 & 92469 & 0.825 & 17658 & 1429 & 112679 & 63.51 \\
\hline $\mathrm{G}$ & 3.31 & 147 & 125719 & 0.823 & 23215 & 2958 & 153426 & 63.21 \\
\hline
\end{tabular}

${ }^{\dagger} \Delta T_{0}=T_{02}-T_{01} ; \eta_{\mathrm{m}}^{0}=0.99$.

\section{NOMENCLATURE}

$C_{\mathrm{w}} \quad$ tangential velocity $[\mathrm{m} / \mathrm{s}]$

$C_{\mathrm{r}} \quad$ radial velocity $[\mathrm{m} / \mathrm{s}]$

$U_{2} \quad$ peripheral velocity of the rotor $[\mathrm{m} / \mathrm{s}]$

$\dot{m} \quad$ net mass flow rate $[\mathrm{kg} / \mathrm{s}]$

$\dot{m}_{\mathrm{t}} \quad$ total mass flow rate $[\mathrm{kg} / \mathrm{s}]$

$\Delta \dot{m} \quad$ fluid loss $[\mathrm{kg} / \mathrm{s}]$

$n_{\mathrm{r}} \quad$ number of rotor blades

$N \quad$ rotor rotational velocity [rpm]

$p \quad$ static pressure $\left[\mathrm{N} / \mathrm{m}^{2}\right]$

$p_{0} \quad$ stagnation pressure $\left[\mathrm{N} / \mathrm{m}^{2}\right]$

$P \quad$ total shaft power [W]

$P_{\mathrm{a}} \quad$ aerodynamic losses [W]

$P_{\mathrm{c}} \quad$ power consumed in the compression process [W]

$P_{\text {is }} \quad$ isentropic compression power [W]

$P_{\mathrm{r}}+P_{\mathrm{m}}$ mechanical losses [W]

$P_{\mathrm{r}} \quad$ disc friction power losses [W]

$P_{\text {util }} \quad$ useful power [W]

$P_{\text {vol }} \quad$ volumetric losses [W]

$r \quad$ radius [m]

$R_{\mathrm{c}} \quad$ pressure ratio

$\mathcal{R}_{\mathrm{g}} \quad$ curvature radius at axial region of the rotor $[\mathrm{m}]$

$s^{*} \quad$ position along the stream tube [m]

$T \quad$ static temperature [K]

$T_{0} \quad$ stagnation temperature [K]

$\beta_{2} \quad$ flow exit angle [degree]

$\beta_{\infty 2} \quad$ geometric angle of the blade at exit [degree]

$\eta \quad$ global efficiency

$\eta_{\mathrm{c}} \quad$ isentropic efficiency

$\begin{array}{ll}\eta_{\infty \mathrm{r}} & \text { politropic efficiency of impeller } \\ \eta_{\mathrm{vol}} & \text { volumetric efficiency } \\ \eta_{\mathrm{m}}^{0} & \text { bearing efficiency } \\ \sigma_{2} & \text { slip factor } \\ \bar{\sigma} & \text { hypothetical slip factor } \\ \omega & \text { rotational velocity }[\mathrm{rad} / \mathrm{s}]\end{array}$

\section{Acknowledgements}

The authors wish to thank the Brasilian National Research Foundations - CNPq for the financial support offered to the second author.

\section{References}

Bammert, K., Rautenberg, M. and Wittekindt, W. (1979) Matching of turbo-components described by the example of impeller and diffuser in a centrifugal compressor, Part I: Aerothermodynamic coupling of impeller and diffuser, Part II: Optimised stage efficiency of a centrifugal compressor, Transactions of the ASME, Journal of Engineering for Power, Paper No. 79-GT/Isr-9, pp. 59-65.

Benevenuto, F.J. (1996) Estudo paramétrico de uma mini turbina a gás do tipo radial, São Carlos, SP, Brasil. 182 p. M.Sc. Thesis, Escola de Engenharia de São Carlos, Universidade de São Paulo.

Came, P.M. (1978) The development, application and experimental evaluation of a design procedure for centrifugal compressors, Proceedings of the Institution of Mechanical Engineers, 192(5), 49-67.

Clements, W.W. and Artt, D.W. (1987) The influence of diffuser channel geometry on the flow range and efficiency of a centrifugal compressor, Proceedings of the Institution of Mechanical Engineers, Part A, 201(A2), 145-152.

Cohen, H., Rogers, G.F.C. and Saravanamutoo, H.I.H. (1987) Gas Turbine Theory, 3rd ed., Longman Scientific \& Technical, England, p. 114.

Kenny, D.P. (1984) The history and future of the centrifugal compressor in aviation gas turbines, Society of Automotive Engineers, Oct. SAE Paper 841635, 15 p. 
Rosolen, C.V.A.G. (1994) Desenvolvimento analítico e numérico de um compressor centrífugo subsônico de baixa potência, São Carlos, SP, Brasil. 148 p. M.Sc. Thesis, Escola de Engenharia de São Carlos, Universidade de São Paulo.

Senoo, Y. (1987) Pressure losses and flow field distortion induced by tip clearance of centrifugal an axial compressors, JSME International Journal, 30(261), 375-385.
Stow, P. (1989) The development of advanced computational methods for turbomachinery blade design, International Journal for Numerical Methods in Fluids, 9(8), 921-941.

Takeda, A.S. (1987) A centrifugal compressor design assessment for a small gas turbine, Cranfield. 161 p. M.Sc. Thesis, School of Mechanical Engineering, Cranfield Institute of Technology. 


\section{ait \\ ENERGY MATERIALS}

M A N E Y publishing

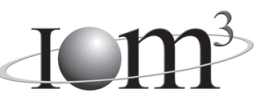

\section{Materials Science \& Engineering for Energy Systems}

Maney Publishing on behalf of the Institute of Materials, Minerals and Mining

The Institute of Materials, Minerals \& Mining

Economic and environmental factors are creating ever greater pressures for the efficient generation, transmission and use of energy. Materials developments are crucial to progress in all these areas: to innovation in design; to extending lifetime and maintenance intervals; and to successful operation in more demanding environments. Drawing together the broad community with interests in these areas, Energy Materials addresses materials needs in future energy generation, transmission, utilisation, conservation and storage. The journal covers thermal generation and gas turbines; renewable power (wind, wave, tidal, hydro, solar and geothermal); fuel cells (low and high temperature); materials issues relevant to biomass and biotechnology; nuclear power generation (fission and fusion); hydrogen generation and storage in the context of the 'hydrogen economy'; and the transmission and storage of the energy produced.

As well as publishing high-quality peer-reviewed research, Energy Materials promotes discussion of issues common to all sectors, through commissioned reviews and commentaries. The journal includes coverage of energy economics and policy, and broader social issues, since the political and legislative context influence research and investment decisions.

\section{CALL FOR PAPERS}

Contributions to the journal should be submitted online at http://ema.edmgr.com

To view the Notes for Contributors please visit: www.maney.co.uk/journals/notes/ema

Upon publication in 2006, this journal will be available via the Ingenta Connect journals service. To view free sample content online visit: www.ingentaconnect.com/content/maney

For further information please contact:

Maney Publishing UK

Tel: +44 (0)113 2497481 Fax: +44 (0)1132486983 Email: subscriptions@maney.co.uk

or

Maney Publishing North America

Tel (toll free): 8662975154 Fax: 6173546875 Email: maney@maneyusa.com

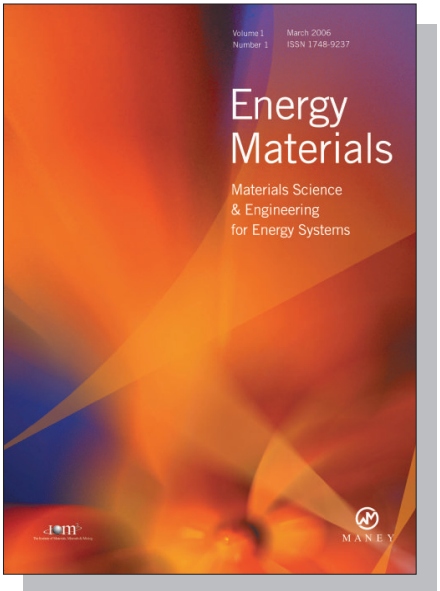

EDITORS

Dr Fujio Abe

NIMS, Japan

Dr John Hald, IPL-MPT, Technical University of Denmark, Denmark

Dr R Viswanathan, EPRI, USA

\section{SUBSCRIPTION INFORMATION}

Volume 1 (2006), 4 issues per year

Print ISSN: 1748-9237 Online ISSN: 1748-9245

Individual rate: $£ 76.00 / U S \$ 141.00$

Institutional rate: $£ 235.00 /$ US $\$ 435.00$

Online-only institutional rate: $£ 199.00 / U S \$ 367.00$

For special $\mathrm{IOM}^{3}$ member rates please email

subscriptions@maney.co.uk

\section{For further information or to subscribe online please visit www.maney.co.uk}



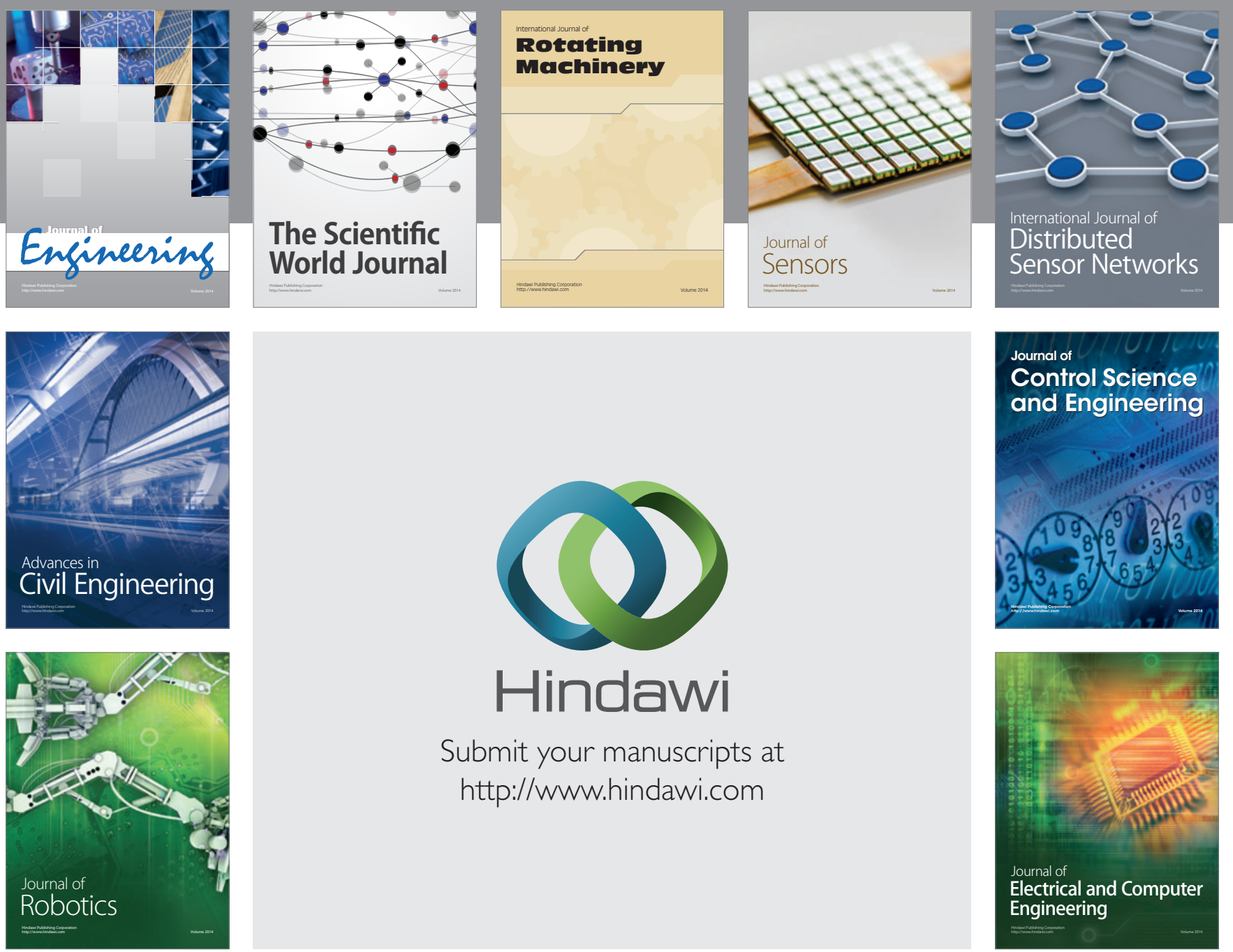

Submit your manuscripts at

http://www.hindawi.com
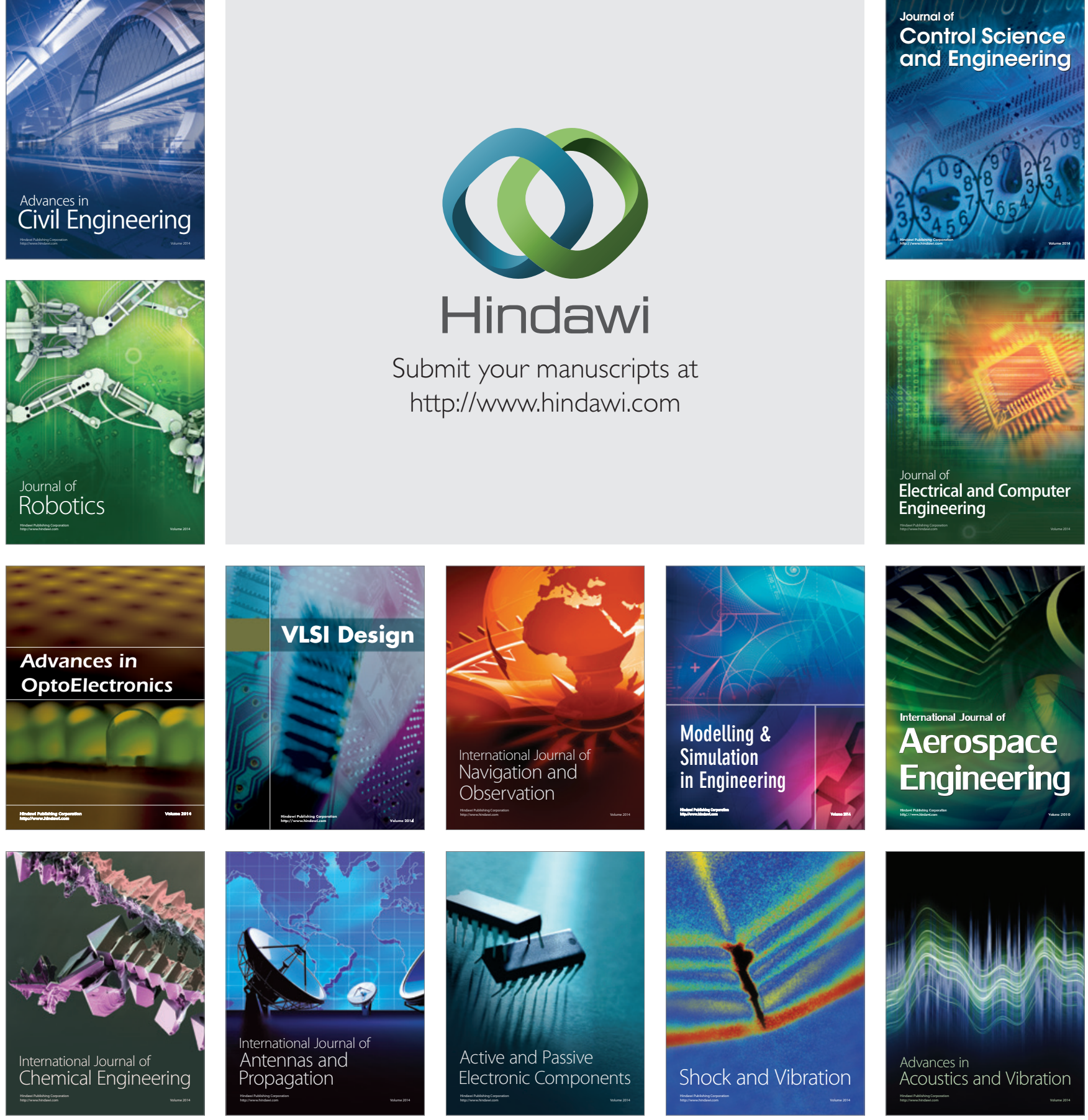